\title{
A perna coxa da tecnologia. - Fantasias totalitárias dos Náufragos da Polissemia na Cibercultura \\ Fclipe Pcna*
}

\begin{abstract}
RESUMO
Levando em conta os simbolos de uma das representações mitológicas mais significativas sobre a técnica, a de Hefestos, o deus coxo, tentamos resgatar o alerta sobre a ambigüidade e as limitações da tecnoiogia. Nosso principal objetivo é discutir algumas das imagens da subjetividade no âmbito da cibercultura e suas conseqüências nas formas de socialização e apreensāo da realidade na contemporaneidade. Partimos da hipótese de que sob o modelo de sujeito descentrado e sem limites presente no imaginário das novas tecnologias, há um individuo que chamamos de náufrago da polissemia, ou seja, sob a metáfora dos mares polissêmicos, na verdade naufraga um sujeito incapaz de dar conta dessas múltiplas significaçōes. $E$ esse naufrágio pode revelar fantasias totalitárias de controle ilimitado sobre a vida humana, com desejos de transcender, inclusive, a própria morte.
\end{abstract}

\section{ABSTRACT}

Following the symbolism of one of the most significant mythological representations of technique - the image of Haefestus, the limping God we attempt to approach the traditional admonitions regarding the ambiguity and limitations of technology. The main goal of this article is to discuss some of the representations of subjectivity in the sphere of cyberculture, as well as its consequences on forms of socialization and on the apprehension of reality in contemporary times. We defend the hypothesis that it is possible to identify a certain species of individual present in the imaginary related to the new technologies - an individual that we propose to define as a "castaway of polissemy". In other words, under the metaphor of the castaway there is a shipwrecked subject, incapable of handling all these multiple meanings. This shipwreck discloses a set of totalitarian fantasies of unlimited control over human life, with a longing for transcending death itself.

\footnotetext{
*Jornalista, doutor em Letras pela PUC-Rio, professor de telejornalismo e jornalismo politico na UFF.
} 


\section{Mitos}

Os sistemas de simbolização da narrativa mítica grega podem ser divididos sob os signos da caça, onde há o domínio do espaço; do cultivo, onde há o domínio do tempo; e dos metais, onde o homem se coloca no lugar do próprio tempo, já que perante a imagem de que os metais germinam no interior da terra, como num grande útero, se sobrepõe o homem como acelerador deste processo.

Com a emergência da sacralidade telúrica ao lado da celeste, quem vai emblematizar essa última idade simbólica será Hefestos, o deus artesão, o deus da técnica, cuja etimologia se transcreve por água que queima. Habilidoso e requintado, terá como principal atributo o dom de ligar e desligar, de atar e desatar, e será o paradigma divino do complexio oppositorum, encontrado também nos heróis. O Deus da ambigüidade é quem ata Prometeu à coluna e também consola-o; tem grande habilidade, mas é coxo; é o mais feio e repelente dos deuses, porém casado com a mais bela do Olimpo, Afrodite, que the trai com o pernicioso Ares, seu companheiro na Ilíada.

São quatro suas principais criações: o trono de ouro para sua mãe, Hera; Pandora, o instrumento de punição para os homens; a rede mágica, onde vai prender os adúlteros Ares e Afrodite; e a famosa armadura de Aquiles, que fez do melhor dos aqueus o portador do fogo de Hefestos.

Depois da briga com Agamêmnon pela escrava Briseida, que acontece no primeiro canto da Ilíada, Aquiles, aviltado em sua honra (timé, para os gregos), se retira do campo de batalha, só retornando no décimo oitavo canto, sob o pretexto da morte de Pátroclo, seu melhor amigo. $\mathrm{O}$ afastamento serve de tempo ritual para que se prepare o retorno do herói, que pede à mãe uma nova armadura, pois a sua tombara junto com o amigo. Tétis, então, se dirige a Hefestos, que confecciona a famosa peça.

É interessante notar as ligações entre Deus e herói. Aquiles gravita na órbita simbólica de Hefestos, ambas as figuras sendo marcadas pela marginalidade. $\grave{A}$ areté (excelência) do primeiro corresponde a tekhné, a habilidade artesanal, do segundo. Hefestos é um Deus coxo e o único que tem oficio no Olimpo.

A armadura é o que torna possível a volta de Aquiles. Não só para a defesa do herói, mas, principalmente, como instrumento de sua glorificação. Hefestos assume o papel de seu paraninfo para que ele possa se tornar o melhor dos aqueus. No gigantesco escudo, confeccionado com uma liga de vários metais nobres, ele imprimirá doze figuras de representação da civilização grega.

Desta forma, Aquiles será o representante de todos aqueles valores culturais e civilizacionais inscritos no escudo, cuja técnica usada para forjálo torna-o quase indestrutivel. Ele carrega todos os motivos da cultura aquéia 
segundo a representação criada por Hefestos: a genealogia cósmica, a agricultura, a pecuária, a vidicultura, o casamento, a guerra, os cultos, a vida palaciana, etc. A cultura está escudando o herói, que, desta forma, não volta sozinho ao campo de batalha.

É interessante notar como o grande herói grego entrega sua vida ao Deus da técnica. É ela que marcará sua triunfante volta ao campo de batalha e o protegerá dos perigos da guerra. Ao mesmo tempo, entretanto, a narrativa mitológica alerta que o Deus é coxo, ambiguo. Sua técnica gera beleza, mas sua própria aparência é horripilante. Ele não consegue usar a habilidade para mudar a si mesmo, ou seja, apesar de dominar a tecnologia, a natureza ainda continuará impondo-lhe limites.

Se, conforme ensina Junito Brandão, o mito "expressa o mundo e a realidade humana, cuja essência é uma realidade coletiva, que chegou até nós através de várias gerações", ${ }^{1}$ então o alerta sobre a ambigüidade da tecnologia demonstra ter raiz arquetípica. E o arquétipo, etimologicamente, pode ser traduzido como um modelo primitivo, o que, segundo Jung, constitui o conteúdo do inconsciente coletivo, a herança das vivências anteriores. Mas não queremos enveredar por estes conceitos.

Apenas queremos deixar registrado que entender o mito também significa entender-se, ou seja, participar da teia de significações que, em última instância, constitui o que chamamos de realidade. Pois ela, a realidade, nunca é unicamente (ou majoritariamente) racional. É preciso fazer a equivalência conceitual que se expressa através do simbolo, reconhecer a linguagem, estar atento às imagens, enfim, nas palavras de Goethe, "entender as relações permanentes da vida", "pois os símbolos da mitologia não são fabricados; não podem ser ordenados, inventados ou permanentemente suprimidos. Esses símbolos são produções espontâneas da psique: cada um deles traz em si, intacto, o poder criador de sua fonte". ${ }^{2}$

Mais do que a longa trajetória que os mitos da tecnologia percorrem na cultura ocidental, o que queremos demonstrar com essa introdução é a persistência de símbolos e discursos referentes à precaução e ao cuidado com as potencialidades da tecnologia na imaginação ocidental. Alertas que parecem ter sido esquecidos pelos tecnófilos contemporâneos, imersos que estão em fantasias de dominação total da natureza e superação da condição humana, cujo corpo consideram obsoleto.

O objetivo principal deste trabalho é discutir algumas das representações a respeito da subjetividade no âmbito da cibercultura e, principalmente, suas consequiências nas formas de socialização e apreensão da realidade na contemporaneidade. As figurações dessa subjetividade no imaginário das novas tecnologias apontam para um modelo de sujeito sem limites ou fronteiras. Entretanto, parto da hipótese de que esse modelo em realidade deve ser compreendido como sintoma da crise gerada pela multiplicação das 
possibilidades de significação pelo sujeito. Atônito diante da falta de referências desta multiplicação de possibilidades e da própria reordenação espacial e temporal do mundo, há um indivíduo que chamo de náufrago da polissemia, ou seja, sob a metáfora dos mares polissêmicos, na verdade naufraga um sujeito incapaz de dar conta dessas múltiplas significações.

A tecnociência contemporânea, em seu impulso fáustico, ${ }^{3}$ tem ambições gnósticas no sentido em que se aproxima de uma forma de culto religioso da tecnologia. Mas, para isso, precisa produzir imagens e discursos que corroborem sua estratégia e formem um impulso mental dirigido às fantasias que povoam o imaginário tecnológico, conforme sugerido por Lucien Sfez e desenvolvido por Erick Felinto:

No caso das novas tecnologias, o vôo da imaginação tem alcançado alturas estratosféricas. (...) Seu sentido de novidade radical faz parte das imagens construidas ao redor delas. (...) Associadas ao absolutamente novo, fantasias ancestrais funcionam como muletas para a aceitação daquilo que aparentaria ser inteiramente incompreensivel para nossas limitadas mentes, ao mesmo tempo em que ampliam o poder $e$ fascinio das novas tecnologias. ${ }^{4}$

No interior das discussões sobre as subjetividades digitais, pretendo abordar especificamente duas das fantasias mais presentes no que poderíamos chamar de sujeito da tecnologia (o desejo de transcendência ligado ao tema do pós-humano e a supressão de qualquer limite para o exercício da sociabilidade possibilitada pelas identidades descentradas) e propor uma reflexão crítica sobre seus desdobramentos. Entre eles, aquele que me parece o mais grave: o anseio de uma nova totalidade que pretende exercer o controle ilimitado sobre a vida humana, transcendendo, inclusive, a própria morte.

A tecnologia é ambígua e limitada. Uma de suas representações mitológicas mais significativas refere-se a um Deus coxo, e nossa hipótese leva em conta essa imagem. O alerta sobre os perigosos desdobramentos de suas fantasias está presente na cultura ocidental há muito tempo, mas é preciso resgatá-lo. Não se trata apenas de apontar os delírios utópicos dos tecnófilos, mas de refletir sobre suas conseqüências. Por outro lado, também não desejo enveredar pelo caminho tecnófobo. Muitas análises sobre a cibercultura já partem de princípios apocalípticos e referem-se apenas a possibilidades fáusticas e conclusões negativas. Mas é preciso admitir que determinadas abordagens do fenômeno tecnológico podem ainda revelar potencialidades que se aproximem mais de uma visão prometeica do domínio técnico, embora a opção pelo ceticismo seja imprescindível para manter a distância analítica.

A tecnologia é coxa. Manca da perna esquerda, mas caminha muito bem com a direita. Talvez seja esse o problema. 


\section{Pós-humanos}

O desejo de dominar a natureza sempre escondeu a verdadeira obsessão do homem: dominar o caos, ou, em outras palavras, ter previsões seguras que evitassem a instabilidade do desconhecido. Para isso, ele inventou a ciência e tratou logo de criar leis deterministas que dessem estabilidade aos fenômenos naturais. A fisica de Aristóteles, a mecânica de Newton ou a abóboda de Ptolomeu tinham a função primordial de ordenar os acontecimentos da natureza, explicando suas origens e tentando prever seus movimentos.

Mas a natureza não se mostrou tão previsivel. Nas últimas décadas, a instabilidade quântica e a teoria do caos vêm ganhando espaço nos estudos das chamadas ciências da complexidade. Para isso o conceito de caos não é mais associado à ausência de ordem, e sim a sistemas dinâmicos e complexos de informação. A imprevisibilidade está presente nestes sistemas, já que eles podem variar de forma aleatória no decorrer do tempo, mas sua utilização avaliza a nova obsessão do homem: o que se quer não é mais dominar a natureza, e sim superá-la. Ou (por que não?) recriá-la. ${ }^{5}$

A pretensão de uma racionalidade absoluta, que se revelou tão perigosa a ponto de fundamentar idéias totalitárias, deu lugar à fantasia tecnognóstica, cuja repugnância pelo corpo motivou o devaneio utópico de engendrar novas formas de vida. Ao enquadrar o caos em um conjunto de sistemas, mesmo que dinâmicos e complexos, o homem tem mais do que a ilusão de controlá-lo: ele agora acredita que pode criá-lo e recriá-lo. Não há outra expressão para definir esta fantasia além do velho complexo de divindade. A contemporânea adoração da tecnologia, em um desejo de transcendência que une ciência e religião, faz com que esse homem acredite que é o próprio Deus.

Mas esse anseio de divindade não é para qualquer um. Conforme estabelece o conceito de gnosis, é preciso ter o conhecimento secreto para pertencer ao seleto grupo. É preciso estar inserido nesta casta tecnológica que controla os caminhos da transcendência espiritual por meio do progresso científico. Em outras palavras, o pensamento tecnognóstico forma o que David Noble ${ }^{6}$ chama de visão elitista da ciência, ou seja, uma visão cuja exclusão social parece ser a premissa básica de suas fantasias.

Nessa visão, a referência à condição humana foi ultrapassada, como alerta o sociólogo português Hermínio Martins:

As biotecnologias não buscam meramente facultar melhoramentos cosméticos e mais próteses para organismos humanos e não-humanos, mas criar novas formas de vida. (...) $A$ atual agenda biotecnológica também inclui a criação de formas de vida mistas, biológicas e mecânicas, aproximando a criação de computadores humanos (utilizando chips biológicos em vez de micro-pastilhas de silica). ${ }^{7}$ 
A crítica de Hermínio a esta visão fáustica da técnica, cujos objetivos estão desvinculados do humano, refere-se fundamentalmente a suas ligações com o acúmulo de capital. Em oposição a uma visão prometéica, cuja crença na racionalidade poderia levar a uma tentativa de aliviar a miserável condição humana, a visão fáustica tem como paradigma a prioridade ontológica da técnica sobre a ciência, sem nenhuma preocupação com o humano. É o que ele chama de tirania das possibilidades tecnológicas. Uma tirania a que devemos resistir através "da imaginação moral e da coragem civil de superior ordem". ${ }^{8}$

Mas essa resistência deve dedicar atenção especial ao campo dos discursos e das imagens, ou seja, à construção do imaginário. É nesta parte da crítica de Martins que queremos nos fixar. Embora a divisão entre impulsos fáusticos e prometéicos já tenha sido amplamente discutida, a abordagem de Hermínio sobre os sonhos e fantasias presentes na ficção científica ainda carece de estudos. ${ }^{9}$ Mais particularmente seu diálogo com Donna Haraway:

A criação de vida artificial mista e tecnoformas que emulam a mente têm, talvez surpreendentemente, sido bem recebidas $e$ elogiadas pela ficção cientifica e por alguma filosofia feminista. As emoções ontológicas induzidas pela transgressão das espécies e das fronteiras categoriais é (sic) ai geralmente entendida como suporte para o desejo feminista de esbater os sexos, os gêneros e os geradores. ${ }^{10}$

As críticas de Hermínio têm endereço certo: o clássico texto Manifesto Ciborgue, ${ }^{11}$ de Donna Haraway, onde ela defende que já somos todos ciborgues, pois fazemos uso de próteses tecnológicas, entendendo-se como prótese até mesmo uma simples vacina contra a gripe. Para Haraway, o ciborgue não é apenas uma figura de fiç̧ão científica ou uma realidade futura, mas sim um símbolo da nova identidade tecnológica. Nesse sentido, ela pretende romper com as tradicionais distinções binárias do ocidente, como as dicotomias masculino/feminino, branco/negro e espírito/corpo, entre outras. Para ela, este rompimento é libertário, já que seu texto é exatamente o que o nome propõe, um manifesto, ou seja, um panfleto político feminista que defende a utilização da noção de ciborgue para pensar uma subjetividade livre das amarras totalitárias do "falogocentrismo" ocidental.

Para Martins, o igualitarismo e a desconfiança por polaridades assimétricas, como a masculino/feminino por exemplo, não requerem uma ontologia gnóstica de cancelamento de todos os dualismos. Nessa linha, a proposta de Haraway está mais para uma fantasia ou sonho: "não parece claro que o igualitarismo moral implique necessariamente a abolição de todas as separações ontológicas: esse, é claro, era o sonho gnóstico de transcender a diáspora dos seres". ${ }^{12}$ 
$\mathrm{Na}$ visão tecnológica contemporânea, a fantasia de abolição das dicotomias também encontra eco na crença de que o conceito de informação é mais importante do que a idéia de materialidade. A partir daí, por exemplo, o par essência/aparência estaria definitivamente obsoleto, se considerada a fantástica velocidade dos fluxos de informação transmitidos em tempo real. No mesmo raciocinio, desbancariamos a dicotomia original/réplica, natural/ artificial, e outras tantas, até chegar ao humano/não-humano, e, porque não dizer, ao eu/outro. Ou seja, o desejo de transcender a "diáspora dos seres", conforme a já citada proposição de Martins, leva-nos a refletir se essa suposta idéia igualitária não esconderia um anseio de totalidade.

Para Katherine Hayles, ${ }^{13}$ a argumentação de que o conceito de informação supera a materialidade produz fantasias de corpos digitais, desmaterializados. Tais corpos poderiam tomar a forma de ciborgues, cujas subjetividades nada mais seriam do que puros padrões de informação. Entretanto, a própria Hayles defende a idéia de que o suporte material é também fator determinante na natureza da informação. Só que os sonhos gnósticos desejam até a conversão do não informacional em informação desmaterializada, em um claro impulso de se aproximar da metafísica neo-platônica da luz, o que, segundo Martins, seria "o momento de consumação do progresso tecnológico". ${ }^{14}$

Chegaríamos então ao verdadeiro ápice da fantasia pós-humana, pois se podemos conceber a nós mesmos como padrões de informação, basta descobrir uma maneira de armazenar estes dados para alcançar a imortalidade. A tecnofania declara o fim da morte e a libertação dos limites do corpo, este obsoleto pedaço de museu. "É um desejo de totalidade, oculto no ideal de unidade absoluta" conforme observa Erick Felinto. ${ }^{15}$

Mas, sendo ou não fantasia, esse desejo traz consigo toda a ontologia do impulso fáustico descrito por Hermínio Martins. O anseio pós-humano pode levar a uma realidade sub-humana, e pior ainda, uma realidade cientificamente justificada. Como muito bem nos lembra Paula Sibilia em sua dissertação de mestrado, da mesma forma que "as doutrinas e práticas eugênicas explicavam cientificamente o racismo algumas décadas atrás, agora surgem outras formas igualmente 'legítimas' de discriminação categórica". ${ }^{16} \mathrm{Em}$ uma de suas linguagens de representação mais clássicas da fantasia, o cinema, o homem é capaz de reproduzir essas formas com assustadora competência, como é o caso do filme Gattaca, cujo enredo traz a idéia de que os cidadãos não projetados geneticamente são considerados inválidos.

O projeto fáustico é bem exemplificado neste filme. A inferioridade é cientificamente justificada e o planejamento genético dá origem a uma casta superior e uniforme. É, mais uma vez, o ideal de unidade absoluta confirmando $o$ anseio de totalidade. Mesmo que as fantasias tecnológicas também tratem da fragmentação da identidade, o que é assunto para a nossa próxima discussão. 


\section{Identidades descentradas}

A atemporalidade e a imaterialidade presentes nos fluxos de informação que formam o ciberespaço permitem a realização de desejos de forma virtual, em um verdadeiro laboratório existencial, liberto de qualquer tipo de obstrução. Parece o fim dos limites impostos ao humano pelo corpo. Um deficiente fisico pode correr a maratona, um sujeito com acrofobia pode pilotar um avião, homens podem ser mulheres e vice-versa, em um exercício lúdico de todas as possibilidades que possam se apresentar.

É a multiplicação/descentramento das identidades. A experiência da liberdade para a(s) subjetividade(s) contemporânea(s). Idéia defendida por teóricos como Sherry Turkle, por exemplo, para quem o sujeito na rede pode ser múltiplo, maleável e mutável. Em sua análise, Turkle chega a afirmar que as novas tecnologias constituem uma confirmação pragmática das teorias pós-modernas sobre o sujeito, elaboradas por teóricos franceses que foram seus professores: "más de veinte años después de haberme encontrado con las ideas de Lacan, Foucault, Deleuze e Guattari, las reencuentro em mi nueva vida en los mundos mediados por ordenador". ${ }^{17}$ Idéias que, segundo ela, a haviam intrigado e confundido durante seu crescimento intelectual, mas que agora se apresentam de forma clara e direta: "en los $M U D$, uno puede ser mucha gente y mucha gente puede ser uno". ${ }^{18}$

Só que nem tudo é tão claro e direto assim. As fantasias inerentes a estas promessas da tecnologia não levam em conta, pelo menos, dois aspectos básicos. O primeiro é que as tais capacidades ilimitadas do sujeito em rede se esvaem diante da vasta dimensão do ciberespaço e de seu excesso de informações, que impõem a necessidade de agentes para que a navegação prossiga. Em outras palavras, há limites, como argumentam Fernanda Bruno e Paulo Vaz: "para que essa massa de informações se aproxime ou seja apreendida por nossas medidas humanas, é preciso que partilhemos nossas atividades de navegação, busca e seleção das informações com os diversos dispositivos técnicos que habitam a rede". ${ }^{19}$

E além dos limites de nossa capacidade cognitiva, há outro aspecto a ser considerado para a crítica das múltiplas identidades: o possível fortalecimento de uma identidade mestra no usuário da rede, em moldes mais próximos à abordagem racional do sujeito do iluminismo, potencializada como resposta às facilidades de multiplicação das subjetividades no ambiente tecnológico e como busca de um porto seguro diante da instabilidade que essa multiplicação provoca. É nesse aspecto que quero me fixar, principalmente porque ele talvez reflita o mesmo desdobramento enfocado no item anterior: a produção de uma nova totalidade.

Não parece difícil concordar com a idéia de que, no ciberespaço, é possível assumir as mais variadas identidades: sexuais, religiosas, ideológicas, etc. $\mathrm{Na}$ 
verdade, essas diferenças deixam de existir, pois não determinam as relações. Uma utopia igualitária viabilizada por uma suposta democracia digital. Mas essa completa indistinção já é, ela própria, uma proposta totalizadora. Além disso, um dos aspectos multiplicadores dessas possibilidades identitárias é a idéia de que o anonimato diminui o potencial segregador e as inibições. $E$ ela não trata apenas da possibilidade de, em um mesmo chat, estarem presentes um padre e um cafetão, por exemplo. $O$ anonimato vai além, funcionando como libertador dos padrões morais, políticos e, principalmente, estéticos da sociedade de consumo contemporânea. Como afirma Margaret Wertheim, "um dos atrativos do ciberespaço é precisamente o alívio do inexorável escrutinio físico que se tornou uma marca registrada da vida nos EUA de hoje". ${ }^{20}$ (Não só nos EUA)

O fato é que, na comunicação mediada por computador, o reconhecimento de uma (ou mais) identidade(s) no outro parece ser consequiência da comunicação, "ao contrário da comunicação tradicional, em que a identidade é a base sobre a qual se dá o processo comunicativo", ${ }^{21}$ conforme conclui Márcio Gonçalves. Em um trabalho sobre o amor virtual, ${ }^{22}$ Márcio defende que os relacionamentos virtuais podem ser relacionamentos efetivamente plenos, sem a necessidade do "real físico". E ainda há a vantagem da liberação das fantasias produzidas pelo anonimato, além da descoberta de possibilidades que seriam inibidas em um relacionamento tradicional. Márcio refuta a idéia de que há fuga da realidade e ilusão de proximidade neste tipo de relação, argumentando que as "relações presenciais" sempre foram virtuais, construidas a partir de imagens sobre o outro, e que a chamada presença pode revelar uma verdadeira ausência, caracterizada, na fluidez da pósmodernidade, pelo desejo de relação sem a disposição do compromisso.

Se partirmos ainda para interpretações cognitivistas da cibercultura, é possivel pensar o próprio hipertexto como um dispositivo produtor de subjetividades. Experiências de descentramento semântico e quebras da cadeia significado/significante, viabilizadas pela estrutura fluida da rede, envolvem o que Landow ${ }^{23}$ chama de wreader, uma junção das palavras inglesas reader e writer, que significam leitor e escritor. O pesquisador Vinícius Pereira usa o termo "lecritor" para pensar esse envolvimento em processos de multilinearidades, multivocalidades e interatividade. E mesmo admitindo que "não há nada de novo sob o sol"24 da hipertextualidade no que se refere a esses processos, já que o leitor sempre produziu sentidos no texto lido e a multilinearidade já estaria presente nos textos ficcionais de autores como Cortazar e Borges, o professor Vinícius ressalta os efeitos cognitivos do hipertexto na cultura, ao fazer "emergir mares polissêmicos nos quais a produção de significados não encontra esteio na lógica ocidental atrelada ao uno, ao idêntico, ao categorizado, ao não contraditório". 25 
Pois é justamente aí que reside parte do problema. O sujeito da contemporaneidade pode se afogar nesses mares polissêmicos. E o medo do afogamento, gerado pelas mudanças aceleradas e a dissolução de certezas e referenciais, produz uma tentativa desesperada de encontrar alguma estabilidade diante da reordenação espacial e temporal do mundo. É nesse sentido que podemos estar diante de um movimento contrário ao descentramento identitário, no qual o eu correspondente ao sujeito da consciência concebido pela filosofia moderna seja usado como bote salvavidas pelos náufragos da polissemia.

Em artigo sobre subjetividade e novas tecnologias ${ }^{26}$ o professor Francisco Rüdiger caminha nessa mesma direção ao defender a necessidade de relativizar o descentramento do sujeito tecnológico:

A revisão da literatura em que essas teses (do descentramento da identidade) pretendem encontrar suporte empirico e a reflexão critica sobre suas premissas teóricas fornecem-nos, segundo nosso modo de ver, elementos para não somente problematizar essa idéia de que a pluralização dos contextos de vida, hoje em dia, resulta na supressão da noção convencional do eu, como ir além: permite-nos pensar se o que ocorre não é antes, o oposto. ${ }^{27}$

$O$ oposto a que se refere Rüdiger é exatamente o fortalecimento desse sujeito da consciência concebido pelo pensamento moderno. Um sujeito que busca a estabilidade em uma identidade coerente e unificada, como resposta à polissemia do descentramento identitário e da própria teia de conexões da contemporaneidade. Um sujeito que pode acabar se guetificando e, novamente, produzindo totalidades. Talvez seja por isso que, apesar das apostas libertárias da rede e de suas fantasias de democracia e igualdade, nunca se tenha visto tanto fundamentalismo no interior da própria rede. Ao mesmo tempo que ela promove grupos de afinidade, esses próprios grupos promovem o seu fechamento, em um movimento aparentemente paradoxal, mas que revela a motivação segmentária de seus integrantes. ${ }^{28}$

\section{Conclusão}

A sociedade moderna viveu em seu cerne a associação vital da racionalidade com a dominação. Os delirantes cientificistas assassinaram Heráclito e estabeleceram a concepção do real como ser estável, uma realidade organizada e conhecida. Pararam as águas do rio para o banho de um homem racional, habitante do mundo como ser constituído pelo domínio da natureza, reduzido a uma palavra: a tecnologia. O homem moderno quis conhecer para dominar, porém, a razão instrumental deveria estar submetida à razão.crítica, e esta permaneceu apenas no plano do discurso, com pouca interferência efetiva sobre o mundo da praxis. 
A intolerância passou a ser signo dominante. Relógios de ponto e linhas de montagem sustentaram o mito do progresso indefinido. Sociedades fora desta lógica foram tratadas a ferro e fogo, produzindo exemplos aterrorizantes de totalitarismo. Mas eles não serviram de alerta para a tecnocultura contemporânea, que parece enveredar pelo mesmo caminho. Só que agora não basta dominar, é preciso transcender.

A lógica fáustica, desumanizada e controladora, prevalece neste impulso transcendente do capitalismo tardio, que é muito mais requintado em sua estratégia. Relógios de ponto não são mais necessários. O produtor disciplinado foi substituído pelo consumidor controlado, cujo perfil está em algum banco de dados que, por sua vez, também é um produto à venda.

Mas para que a estratégia funcione também é preciso vender fantasias sobre as possibilidades abertas pela dissolução de limites presentes na fragmentação das identidades. Fantasias gnósticas de superação do corpo e exercício lúdico das infinitas potencialidades da cibercultura. Fantasias de democratização das relações pessoais que escondem um ideal de unidade absoluta, cujo anseio de totalidade pode ser detectado a partir de uma perspectiva crítica.

Na outra mão desse movimento, também há um indivíduo atônito diante do ritmo alucinante da contemporaneidade, com suas mudanças aceleradas e decomposição de certezas e referenciais. Um individuo que tenta desesperadamente encontrar alguma estabilidade diante da reordenação espacial e temporal do mundo. Um náufrago da polissemia do ciberespaço, tentando sobreviver em pequenos botes de coerência representados pela suposta unicidade do sujeito da consciência concebido pelo racionalismo moderno, o que pode representar uma outra maneira de também produzir totalidades.

Como no mito de Hefestos, há uma perna coxa na tecnologia. A rede de bits e bytes da contemporaneidade pode até ser um meio privilegiado para exprimir potências de ação de entidades civis organizadas, como as manifestações de Gênova e Seatlle, por exemplo, e sua polissemia talvez seja responsável pelo esmaecimento da rigidez das subjetividades ligadas à sociedade disciplinar. Mas esta parece ser a perna que manca. Há uma outra muito mais forte e determinada, e ela sustenta a dependência ontológica da ciência com relação à técnica, produzindo um impulso desumanizador e totalitário.

O recém falecido Karel Kosik identificou a época em que vivemos com a figura de Grete Samsa, irmã do personagem principal de A Metamorfose (1911) de Kafka, já que ela representa a visão desumanizada sobre o outro. Grete nega a humanidade do irmão ao dispensar o sepultamento e encarregar a empregada de varrê-lo, em um movimento diametralmente oposto à atitude de Antígona na tragédia grega. Para o autor, esta é uma ilustração clara de que, 
nas relações metamorfoseadas do cotidiano, o grotesco substitui o trágico. Se nem a morte tem a capacidade para arrancar os homens da banalidade e da superficialidade, Kosik pergunta se esta mesquinharia teria sepultado definitivamente a possibilidade do trágico e decretado a vitória da antiAntígona: "quem poderia enfrentar a poderosa Grete Samsa, contrapondo-se a ela como uma Antígona moderna?". 29

Se o deus é coxo e o homem naufragou na polissemia, talvez seja tarefa para um ciborgue. ${ }^{30}$

Bibliografia:

BRANDÃO, Junito. Mitologia grega. Vol. 1. Petrópolis. Ed. Vozes. 1993.

CAMPBELL, Joseph. O Herói de mil faces. São Paulo. Cultirx. 1993.

FELINTO, Erick. Por uma crítica do imaginário tecnológico. Novas tecnologias e imagens da transcendência. R.J. cd-rom da Compós. 2002.

FERRAZ, Maria Cristina Franco. "Sociedade tecnológica: de Prometeu a Fausto." IN: Contracampo. Vol. 4. UFF. R.J. 2000.

GONÇALVES, Márcio. Amor virtual. R.J. cd-rom da Compós. 2002.

HARAWAY, Donna. "Manifesto ciborgue." IN: SILVA, Tomaz T. da Antropologia do ciborgue: as vertigens do pós-humano. Belo Horizonte. Autêntica. 2000.

HAYLES, Katherine. How we became posthuman. Virtual bodies in cybernetics, literature and informatics. Chicago. Uiversity of Chicago Press.

1521999.

HOMERO. Allíada. Tradução de Fernando Gomes. R.J. Ediouro. S/d.

KAFKA, Franz. A metamorfose. S.P. Brasiliense. 1995.

KITTO, H.D.F. Os gregos. Coimbra. Armênio Amado editor. 1985.

KOSIK, Karel. O século de Grete Samsa. Tradução de Leandro Konder para folheto impresso no DP de Letras da UERJ em 1995.

LANDOW, George. Teoria del hipertexto. Barcelona . Paidós. 1997.

MARTINS, Hermínio. Hegel, Texas e outros ensaios de teoria social. Lisboa. Ed. Século XXI. 1996.

NOBLE, David. The religion of technology. London. Penguin books. 1999. PENA, Felipe. A volta dos que não foram. R.J. Sette Letras. 1998.

. Biografias em fractais: múltiplas identidades em redes

flexíveis e inesgotáveis. Recife. Cd- rom da Compós. 2003.

PEREIRA, Vinícius Andrade. Dinâmicas contemporâneas da subjetivação.

Metamorfoses das ciências e hipertexto. CD-Rom da Compós. 2000.

RÜDIGER, Francisco. Capítulos de arqueologia espiritual pós-moderna.

Sujeito e objeto na aurora da cibercultura. Porto Alegre. Ed. @. 2002.

SIBILIA, Paula. O homem pós-orgânico. Corpo, subjetividade e tecnologias

digitais. R.J. Relume Dumará. 2002. 
TURKLE, Sherry. La vida em la pantalla. La construcción de la identidad em la era de Internet. Barcelona. Paidós. 1997.

VAZ, Paulo \& BRUNO, Fernanda. "Agentes.com" IN: Contracampo 7. UFF. 2002.

Notas:

'Brandão, pág. 36

${ }^{2}$ Apud Campbell, pág. 15 .

${ }^{3}$ Conforme a diferenciação descrita pelo sociólogo Herminio Martins, que será abordada ao longo deste trabalho, a visão prometeica da técnica está vinculada a uma racionalidade cujo objetivo poderia levar a uma tentativa de aliviar a miserável condição humana, enquanto a visão fáustica desvinculase do humano e baseia-se na prioridade ontológica da técnica sobre a ciência. ${ }^{4}$ Felinto, p. 2.

${ }^{5}$ Idéia que desenvolvi em trabalho apresentado no GT de Comunicação e Cultura da Compós em 2003, sob o título

Biografias em fractais: múltiplas identidades em redes flexiveis e inesgotáveis.

${ }^{6}$ The religion of technology. London. Penguin Books. 1999.

${ }^{7}$ Martins, p. 188

${ }^{8}$ Idem, p. 245.

${ }^{9} \mathrm{E}$ aqui vamos nos ater apenas às suas críticas sobre a ontologia gnóstica de cancelamento de todos os dualismos.

${ }^{10}$ Idem, p. 190.

"IN: SILVA, Tomaz Tadeu da (org). Antropologia do ciborgue.

BH. Ed. Autêntica. 2000.

${ }^{12}$ Ibid, p. 191.

${ }^{13}$ How we became posthuman. Chicago. University of Chicago Press. 1999.

${ }^{14}$ Martins, p. 181.

${ }^{15}$ Felinto, p. 8.

${ }^{16}$ Sibilia, p. 201.

${ }^{17}$ Turkle, p. 23.

${ }^{18} \mathrm{Idem}$.

${ }^{19}$ Vaz e Bruno, p. 26.

${ }^{20}$ Wertheim, p. 19.

${ }^{21}$ Gonçalves, p.3.

${ }^{22}$ Apresentado no GT Sociedade Tecnológica da Compós em 2001.

${ }^{23}$ Landow, p. 31.

${ }^{24}$ Pereira, p. 14.

${ }^{25}$ ibid, p. 16. 
26 "Sociabilidade virtual, subjetivismo moderno e informática." IN: RÜDIGER, F. Capítulos de arqueologia espiritual pós-moderna. Ed@. Porto Alegre. 2002

${ }^{27}$ Rudiger, p. 108.

${ }^{28}$ A mesma motivação segmentária e localizada que produz grupos de discussão sobre os assuntos mais fechados e limitados, no entanto, é capaz de unir esses mesmos grupos em causas profundamente globalizadas, como a batalha de Seatlle e o movimento zapatista, por exemplo.

${ }^{29}$ Kosik, pág.16.

${ }^{30} \mathrm{Com}$ esta ironia, quero apenas confirmar meu ceticismo e, provavelmente, o do próprio Karel kosik.

\footnotetext{
Palavras-chave

1. Cibercultura

2. Comunicação

3. Tecnologia

4. Subjetividades

5. Mito
} 